\title{
Research Paper: Effects of Intramuscular Electrical Stimulation on Symptoms Following Trigger Points; A crossuart Controlled Pilot Study
}

\author{
Monavar Hadizadeh ${ }^{1}$, Siamak Bashardoust Tajali ${ }^{\star}$, Behrouz Attarbashi Moghadam², Shohreh Jalaie ${ }^{3}$, Mahnaz Bazzaz ${ }^{1}$
}

1. MSc. Student, Department of Physiotherapy, School of Rehabilitation, Tehran University of Medical Sciences, Tehran, Iran

2. Assistant Professor, Department of Physiotherapy, School of Rehabilitation, Tehran University of Medical Sciences, Tehran, Iran.

3. Associate Professor, Department of Physiotherapy, School of Rehabilitation, Tehran University of Medical Sciences, Tehran, Iran.

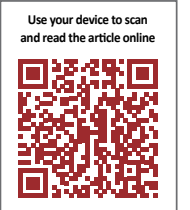

Citation: Hadizadeh M, Bashardoust Tajali S, Attarbashi Moghadam B, Jalaie Sh, Bazzaz M. Effects of Intramuscular Electrical Stimulation on Symptoms Following Trigger Points; A Controlled Pilot Study. Journal of Modern Rehabilitation. 2017; 11(1):31-36. https://doi.org/10.18869/nirp.jmr.11.1.31

https://doi.org/10.18869/nirp.jmr.11.1.31

Article info:

Received: 03 Jul. 2016

Accepted: 26 Oct. 2016

\section{Keywords:}

Myofascial pain syndrome, Intramuscular electrical stimulation, Dry needling, Trigger point, Upper trapezius.

\section{ABSTRACT}

Introduction: Myofascial Pain Syndrome (MPS) is a common disorder of musculoskeletal system. About one third of the people with musculoskeletal disorders have been diagnosed as having MPS. It is a painful condition caused by trigger points. A variety of treatment approaches are used to cure MPS and its associated disorders. This study aimed to investigate the effects of single session Intramuscular Electrical Stimulation (IMES) through dry needling on pain and Range Of Motion (ROM) following trigger points in upper trapezius.

Materials and Methods: Sixteen volunteers with active trigger points in upper trapezius were randomly divided into two groups: 1) the IMES treatment group (8 females) and 2) placebo group ( 8 females). In the IMES group, trigger points of the affected side were injected through dry needling, then a burst current $(2 \mathrm{~Hz})$ was applied on the muscle while the electrical stimulation steadily increases to form a pain free contraction for the patient. In placebo group, the procedure was exactly the same but there was no applied electrical stimulation through dry needling. Pain sensation by Visual Analog Scale (VAS) and cervical flexion ROM were measured before treatment, immediately after treatment and one week later by another blinded researcher.

Results: VAS scores showed improvement in both groups at the end of the treatment session and also one week later. There was no significant difference between the groups; IMES and placebo in terms of the VAS after treatment session. However, the pain scores were substantially decreased in the IMES group one week after the intervention. The ROMs were significantly lower in placebo group one week after treatment. There was no significant correlation between improvement and duration of symptoms.

Conclusion: Both IMES and placebo methods might be effective in relieving symptoms of patients with the MPS in upper trapezius; however, patients following the IMES treatment showed higher level of improvement during one week after the intervention. Further relevant studies with higher number of volunteers and different treatment protocols are necessary to get high quality evidence.

* Corresponding Author:

Siamak Bashardoust Tajali, PhD

Address: Department of Physiotherapy, School of Rehabilitation, Tehran University of Medical Sciences, Tehran, Iran.

Tel: +98 (21) 77685105

E-mail: s_bashardoust@sina.tums.ac.ir 


\section{Introduction}

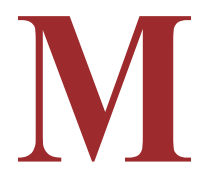

yofascial Pain Syndrome (MPS) is a painful condition due to active trigger points. MPS can be local, caused by a group of muscles functionally related to each other, or be generalized involving several areas [1]. About one third of the patients with musculoskeletal complaints meet diagnostic criteria for MPS [2], which is characterized by painful taut band with referral pain and Local Twitch Response (LTR) [3].

Myofascial Trigger Points (MTrPs) are common causes of musculoskeletal disorders, especially in workplaces [4]. MTrP is a hyperirritable spot in skeletal muscle associated with a hypersensitive palpable nodule in a taut band. The spot is painful on compression and may end in characteristic referral pain and tenderness, as well as motor dysfunction [5]. Taut band is a palpable rope-like hardening of a muscle bearing an MTrP. A taut band usually contains one or more tender trigger points [1]. There are two types of trigger points: active MTrP that causes clinical pain complaint and demonstrates as a tender, preventative full lengthening of the weaken muscle and refers as a patient-recognized pain on direct compression; latent MTrP which is clinically quiescent with respect to spontaneous pain and is painful only in palpation [5]. One of the most common muscles for the trigger point is upper trapezius muscle. The trigger point in this muscle is accompanied with many disorders. The MTrPs in this muscle is a common condition among patients with shoulder complaints, neck pain, undergone mastectomy and chronic tension-type headache [6-11].

Intramuscular Electrical Stimulation (IMES) is a new treatment modality applied by electrical stimulation through dry needling. Several investigations have reported that IMES can be an effective modality on musculoskeletal pain [12-16]; however, few relevant studies could be found which reported effects of the IMES on myofascial trigger points $[14,16]$. To our knowledge, there is no study comparing the IMES and placebo approaches in patients with the MTrPs. In this controlled pilot study, we aimed to compare the efficacy of the IMES versus placebo treatment in patients with MTrPs in upper trapezius muscle.

\section{Materials and Methods}

Patients with active MTrP in upper trapezius muscle were recruited for this study. The inclusion criteria comprised having active MTrP in upper trapezius muscle; aged between 18 to 40 years; with pain intensity above 3 (based on Visual Analog Scale [VAS]) [17]; not receiving any medical or physical therapy modalities within one month before the study; no history of fibromyalgia, systemic muscle disease, cervical surgery, or diabetes. Patients were informed about the study objectives and treatment protocol prior to the study, and an informed consent form were voluntarily obtained from them. Patients who were pregnant or could not tolerate the intervention were excluded from the study.

The eligible patients were randomly divided into two groups by using simple computerized randomization method [18]. Patients in the first group included 8 volunteers treated under IMES, and patients in the second group $(n=8)$ treated by dry needling without any electrical stimulation (placebo). The IMES was applied by a calibrated electro-acupuncture device (ES-160 by ITO Company) (Figure 1). At first, the investigators identified the most tender MTrPs and marked them on the participants' bodies. Then, a specified sterile dry needle was entered directly to the trigger point up to the one third of the needle length. The electrical stimulation was applied into the trigger point using a crocodile connection. The electrical current applied as a burst frequency of $2 \mathrm{~Hz}$ and pulse width of $200 \mu$ s by cathode electrode, while a round pad was placed on skin around 7th cervical spinous process as the reference electrode (the anode) (Figure 2). In the IMES group, the current intensity increased up to the time of muscular pain release and visible free local contraction. The intensity increased through the intervention to control adaptation development. In the placebo group, the procedure was exactly the same but there was no electrical stimulation under dry needling. The treatment was continued for a period of 10 minutes and just for one session.

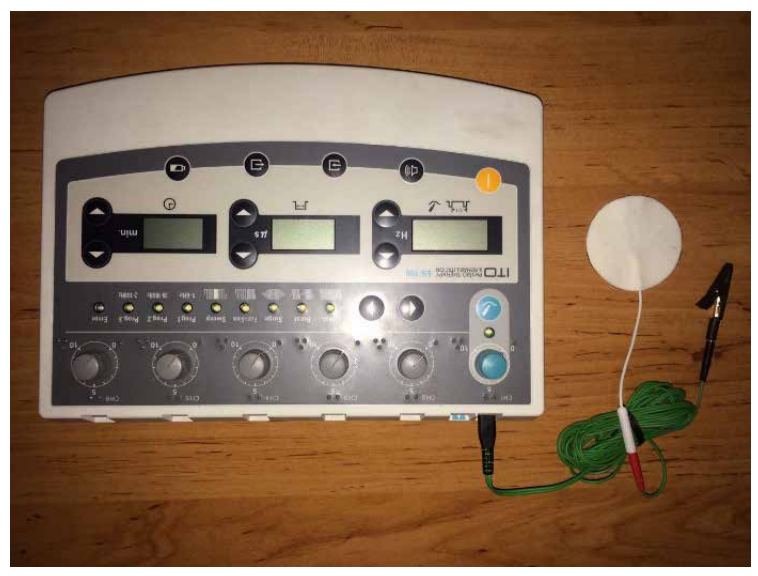

Figure 1. Electro-acupuncture device 


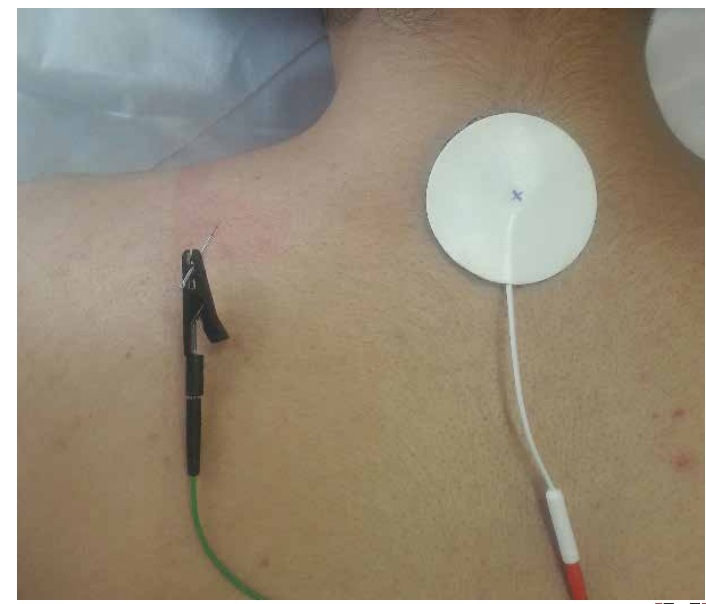

Figure 2. Electrode placement

JMR

The outcome measures were assessed three times; before the treatment, immediately and one week after the treatment. The measurements were performed by another therapist who was blinded to the treatment groups. The assessment tools were a 10-cm VAS to measure pain intensity (the VAS had several anchors between the tails but there were no number on them), and a manual goniometer to measure lateral flexion Range of Motion (ROM) in cervical spine. The VAS helped the examiner to score pain intensity from 0 (no pain) to 10 (worst possible pain). The patient estimated pain by marking along the scale.

\section{Statistical analyses}

The SPSS version 22.0 was applied for statistical analysis. The measurable parameters were analyzed for each group by Kolmogorov-Smirnov test to evaluate normal distribution. The parametric statistical method was performed after confirmation of normal distribution. Oneway analysis of variance (ANOVA) was performed to compare between-group differences and the Pearson correlation coefficient was used to identify relationship between level of improvement and duration of symptoms. Since the age distribution was not normal, nonparametric test (Mann-Whitney U test) was used in statistical evaluation. The $\alpha$ value was considered as 0.05 .

\section{Results}

A total number of 19 patients were eligible for this study. Three patients refused to participate in the study. Therefore, 16 patients with at least one active MTrP in upper trapezius muscle were randomly allocated to the IMES and placebo groups. All 16 patients completed the study. The mean age of the patients was 25.68 years and the mean duration of symptoms was 23.12 months. The participants were approximately similar in clinical and also demographic features (Table 1). Both groups were comparable with respect to the VAS and ROM at baseline (Table 2).

The pain scores of the IMES group were significantly diminished one week after the intervention, while it was unchanged in placebo group $(\mathrm{P}=0.048)$. However, there were no statistically difference between the IMES and placebo groups based on the VAS scores evaluated at the end of the treatment session (Table 2). The ROM was significantly lower in placebo compared to IMES group one week after treatment $(\mathrm{P}=0.048)$, while it was not significantly different between the groups at the end of treatment session (Table 2).

Improvement of pain score $(\mathrm{P}=0.016)$ and $\mathrm{ROM}(\mathrm{P}=0.025)$ were significantly higher in group IMES one week after treatment session (Table 3). There was no correlation between level of improvement and duration of symptoms.

\section{Discussion}

In this controlled pilot study, the researchers evaluated the efficacy of IMES in patients with MTrPs. Our results demonstrated that IMES treatment approach is more effective in decreasing pain intensity compared with the placebo approach. There is no correlation between lowering pain intensity and duration of symptoms.

It has been reported that intramuscular electrical stimulation can lower the pain level in people with myofascial trigger points in upper trapezius and levator scapulae

Table 1. Baseline characteristics of the patients

\begin{tabular}{ccc}
\hline & IMES $(\mathbf{n}=\mathbf{8})$ & Placebo $(\mathbf{n}=\mathbf{8})$ \\
\hline $\begin{array}{c}\text { Age }(\mathrm{y}), \\
\text { Mean } \pm \text { SD }\end{array}$ & $24.63 \pm 6.39$ & $26.75 \pm 6.49$ \\
\hline $\begin{array}{c}\text { Duration of symptoms (mon), } \\
\text { Mean } \pm \text { SD } \\
\text { Gender }\end{array}$ & $22 \pm 17.49$ & $24.25 \pm 12.84$ \\
\hline
\end{tabular}


Table 2. Comparison of clinical data in intramuscular electrical stimulation through dry needling and placebo groups in patients with trigger points in trapezius muscle

\begin{tabular}{ccccc}
\hline & & IMES $(\mathbf{n}=8)$ & Placebo $(\mathbf{n}=\mathbf{8})$ & P \\
\hline Pain (VAS) (0-10) & Pre-treatment & $50.62 \pm 10.19$ & $45.25 \pm 16.99$ & 0.456 \\
& Immediately after treatment & $28.62 \pm 10.16$ & $33.87 \pm 17.54$ & 0.476 \\
& One week after treatment & $17 \pm 13.59$ & $35.25 \pm 19.57$ & 0.048 \\
ROM & Pre-treatment & $28.53 \pm 7.31$ & $30.62 \pm 7.28$ & 0.577 \\
& Immediately after treatment & $32.95 \pm 8.05$ & $29.24 \pm 5.76$ & 0.308 \\
& One week after treatment & $34.74 \pm 3.37$ & $28.72 \pm 5.46$ & 0.019 \\
\hline
\end{tabular}

Table 3. Comparison of improvement level in intramuscular electrical stimulation through dry needling and placebo groups in patients with trigger points in trapezius muscle

\begin{tabular}{ccccc}
\hline & & IMES $(\mathbf{n}=8)$ & Placebo $(\mathbf{n}=\mathbf{8})$ & $\mathbf{P}$ \\
\hline \multirow{2}{*}{ Pain } & Initial improvement & $-22 \pm 9.47$ & $-11.37 \pm 11.85$ & 0.068 \\
& After one week improvement & $-33.62 \pm 15.29$ & $-10 \pm 19.07$ & 0.016 \\
\multirow{2}{*}{ ROM } & Initial improvement & $4.41 \pm 5.59$ & $-1.37 \pm 5.50$ & 0.056 \\
& After one week improvement & $6.20 \pm 6.36$ & $-1.89 \pm 6.58$ & 0.025 \\
\hline
\end{tabular}

Initial improvement=VAS (end of the treatment session) - VAS (before treatment)

After one week improvement=VAS (one week after treatment) - VAS (before treatment)

muscles [14]. Sumen et al. also reported that intramuscular electrical stimulation might improve pain in people with myofascial trigger points in upper trapezius muscle [16]. The result of the present study confirmed results of the mentioned studies. Particular attention has been paid to the injured or overloaded muscle fibers following eccentric and intense concentric contractions in the pathogenesis of the MTrPs. Muscle trauma and repetitive low-intensity muscle overload may create a vicious cycle of events that damage the sarcoplasmic reticulum that increase calcium concentration, shorten the actin and myosin filaments, and impair calcium pump activation $[19,20]$.

The most accepted theoretical concept about MTrP is the integrated hypothesis [19]. It proposes that abnormal depolarization of the postjunctional membrane of motor endplates will produce a localized hypoxic energy crisis [21]. Several studies have confirmed that a Local Twitch Response (LTR) can reduce or even eliminate the typical endplate noise associated with the MTrPs and suggests that it can inactivate the MTrPs $[22,23]$. The LTRs appear to reduce the concentrations of many chemicals found in environment of active the MTrPs, such as sub- stance P [24-26]. Shah et al. had speculated that the drop in concentrations might be results of a local increase in blood flow [25].

Previous relevant studies have reported that electrical stimulation can increase blood circulation [27]. Electrical stimulation-induced contractions can improve circulation and reduce blood stasis [28-30]. Burst-mode transcutaneous electrical nerve stimulation applied at an intensity above the motor threshold causes a transient increase in blood flow and also decreases vascular resistance [31]. It seems that electrical stimulation provided in this study induced contractions, lead to improve circulation and reduce chemical concentrations around the active MTrPs environment. Low level of chemical concentrations, such as substance $\mathrm{P}$, might be the reason of pain relief for the patients with trigger points in trapezius muscle. Moreover, the frequency of the electrical stimulation was set between 2 and $4 \mathrm{~Hz}$ that might help release endorphins and encephalin [32] leading to pain relief. A few number of volunteers is another limitation of this study. Another potential limitation might be inability to follow up long term treatment effectiveness. 
In conclusion, IMES treatment is an effective method to improve symptoms following trigger points. There is no correlation between level of improvement and duration of symptoms. More studies with more volunteers are necessary to confirm the improvement results, investigate the long-term effects and compare with the other interventions.

\section{Acknowledgements}

This research was part of the MSc. accomplishment thesis in physical therapy $(\mathrm{MH})$ and partially funded by the Deputy of Research, School of Rehabilitation-Tehran University of Medical Sciences.

\section{Conflict of Interest}

The authors declared no conflicts of interest.

\section{References}

[1] Mense S, Gerwin D. Muscle pain: Understanding the mechanisms. Berlin: Springer; 2010.

[2] Daniels J, Ishmael T, Wesley R. Managing myofascial pain syndrome sorting through the diagnosis and honing treatment. The Physician and Sportsmedicine. 2003; 31(10):39-45. doi: 10.1080/00913847.2003.11439953

[3] Zhuang X, Tan S, Huang Q. Understanding of myofascial trigger points. Chinese Medical Journal. 2014; 127(24):4271-7. PMID: 25533832

[4] Simons D. Review of enigmatic MTrPs as a common cause of enigmatic musculoskeletal pain and dysfunction. Journal of Electromyography and Kinesiology. 2004; 14(1):95-107. doi: 10.1016/j.jelekin.2003.09.018

[5] Simons D, Travell J, Simons L, Cummings BD. Myofascial Pain and Dysfunction: The trigger point manual. London: Williams \& Wilkins; 1999.

[6] Muñoz-Muñoz S, Muñoz-García M, Alburquerque-Sendín F, Arroyo-Morales M, Fernández-de-las-Peñas C. Myofascial trigger points, pain, disability, and sleep quality in individuals with mechanical neck pain. Journal of Manipulative and Physiological Therapeutics. 2012; 35(8):608-13. doi: 10.1016/j. jmpt.2012.09.003

[7] Lluch E, Nijs J, Kooning M, Dyck D, Vanderstraeten R, Struyf F, Anne Roussel N. Prevalence, incidence, localization, and pathophysiology of myofascial trigger points in patients with spinal pain: A systematic literature review. Journal of Manipulative and Physiological Therapeutics. 2015; 38(8):587-600. doi: 10.1016/j.jmpt.2015.08.004

[8] Ferna'ndez-Lao C, Cantarero-Villanueva I, Ferna'ndez-delas-Pen as C, Del-Moral-A'vila R, Menjo'n-Beltra'n S, ArroyoMorales M. Development of active myofascial trigger points in neck and shoulder musculature is similar after lumpectomy or mastectomy surgery for breast cancer. Journal of
Bodywork \& Movement Therapies. 2012; 16(2):183-190. doi: 10.1016/j.jbmt.2011.01.022

[9] Couppe C, Torelli P, Fuglsang-Frederiksen A, Andersen K, Jensen R. Myofascial trigger points are very prevalent in patients with chronic tension-type headache a double-blinded controlled study. The Clinical Journal of Pain. 2007; 23(1):2327. doi: 10.1097/01.ajp.0000210946.34676.7d

[10] Alonso-Blanco C, Fernández-de-las-Peñas C, FernándezMayoralas D, De-la-Llave-Rincón A, Pareja J, Svensson P. Prevalence and Anatomical Localization of Muscle Referred Pain from Active Trigger Points in Head and Neck Musculature in Adults and Children with Chronic TensionType Headache. Pain Medicine. 2011; 12(10):1453-63. doi: 10.1111/j.1526-4637.2011.01204.x

[11] Bron C, Dommerholt J, Stegenga B, Wensing M, Oostendorp R. High prevalence of shoulder girdle muscles with myofascial trigger points in patients with shoulder pain. BMC Musculoskeletal Disorders. 2011; 12(1):1-12. doi: 10.1186/1471-2474-12-139

[12] Chu J, Takehara I, Li T, Schwartz I. Electrical twitch obtaining intramuscular stimulation (ETOIMS) for myofascial pain syndrome in a football player. British Journal of Sports Medicine. 2004; 38(5):e25. doi: 10.1136/bjsm.2003.010306

[13] Chu J, Yuen K, Wang B, Chan RC, Schwartz I, Neuhauser D. Electrical twitch-obtaining intramuscular stimulation in lower back pain. American Journal of Physical Medicine \& Rehabilitation. 2004; 83(2):104-111. doi: 10.1097/01. phm.0000107485.86594.8b

[14] Lee S, Chen C, Lee C, Lin T, Chan R. Effects of needle electrical intramuscular stimulation on shoulder and cervical myofascial pain syndrome and microcirculation.Journal of the Chinese Medical Association. 2008; 71(4):200-6. doi: 10.1016/ s1726-4901(08)70104-7

[15] Rock J, Rainey C. Treatment of nonspecific thoracic spine pain with trigger point dry needling and intramuscular electrical stimulation: a case series. The International Journal of Sports Physical Therapy. 2014; 9(5):699-711. PMID: 25328832

[16] Sumen A, Sarsan A, Alkan H, Yildiz N, Ardic F. Efficacy of low level laser therapy and intramuscular electrical stimulation on myofascial pain syndrome. Journal of Back and Musculoskeletal Rehabilitation. 2015; 28(1):153-158. doi: 10.3233/ bmr-140503

[17] Collins S, Moore R, McQuay H. The visual analogue pain intensity scale: what is moderate pain in millimetres? Pain 1997; 72(1):95-97. doi: 10.1016/s0304-3959(97)00005-5

[18] Suresh K. An overview of randomization techniques: An unbiased assessment of outcome in clinical research. Journal of Human Reproductive Sciences. 2011; 4(1):8-11. doi 10.4103/0974-1208.82352

[19] Dommerholt J, Fernandez-de-las-penas C. Trigger point dry needling. Amsterdam: Elsevier; 2013.

[20] Gerwin R, Dommerholt J, Shah J. An expansion of simons integrated hypothesis of trigger point formation. Current Pain and Headache Reports. 2004; 8(6):468-75. doi: 10.1007/ s11916-004-0069-x

[21] McPartland J, Simons D. Myofascial Trigger Points: Translating Molecular Theory into Manual Therapy. Journal of 
Manual \& Manipulative Therapy. 2006; 14(4):232-39. doi: $10.1179 / 106698106790819982$

[22] Hong, C, Torigoe Y, Electrophysiological Characteristics Of Localized Twitch Responses In Responsive Taut Bands Of Rabbit Skeletal Muscle. Journal of Musculoskeletal Pain. 1994; 2(2):17-43. doi: 10.1300/j094v02n02_03

[23] Hong C, Lidocaine injection versus dry needling to myofascial trigger point. The importance of the local twitch response. American Journal of Physical Medicine \& Rehabilitation. 1994; 73(4):256-63. doi: 10.1097/00002060-199407000-00006

[24] Shah J, Phillips T, Danoff J, Gerber L. An in vivo microanalytical technique for measuring the local biochemical milieu of human skeletal muscle. Journal of Applied Physiology. 2005; 99(5):1977-84. doi: 10.1152/japplphysiol.00419.2005

[25] Shah J, Danoff J, Desai M, Parikh S, Nakamura L, Phillips $\mathrm{T}$, Gerber L. Biochemicals associated with pain and inflammation are elevated in sites near to and remote from active myofascial trigger points. Archives of Physical Medicine and Rehabilitation. 2008; 89(1):16-23. doi: 10.1016/j.apmr.2007.10.018

[26] Shah J, Gilliams E. Uncovering the biochemical milieu of myofascial trigger points using in vivo microdialysis: An application of muscle pain concepts to myofascial pain syndrome. Journal of Bodywork and Movement Therapies. 2008; 12(4):371-84. doi: 10.1016/j.jbmt.2008.06.006

[27] Yamabata S, Shiraishi H, Munechika M, Fukushima $H_{\text {, }}$ Fukuoka Y, Hojo T, et al. Effects of electrical stimulation therapy on the blood flow in chronic critical limb ischemia patients following regenerative therapy. SAGE Open Medicine. 2016; 4: 205031211666072. doi: 10.1177/2050312116660723

[28] Faghri P, Meerdervort H, Glaser R, Figoni S. Electrical Stimulation-Induced Contraction to Reduce Blood Stasis During Arthroplasty. IEEE Transactions on Rehabilitation Engineering. 1997; 5(1):62-9. doi: 10.1109/86.559350

[29] Broderick B, O'Briain D, Breen P, Kearns S, Laighin G. A pilot evaluation of a neuromuscular electrical stimulation (NMES) based methodology for the prevention of venous stasis during bed rest. Medical Engineering \& Physics. 2010; 32(4):349-55. doi: 10.1016/j.medengphy.2010.01.006

[30] Griffin M, Nicolaides A, Bond D, Geroulakos G, Kalodiki E. The efficacy of a new stimulation technology to increase venous flow and prevent venous stasis. European Journal of Vascular and Endovascular Surgery. 2010; 40(6):766-71. doi: 10.1016/j.ejvs.2010.06.019

[31] Sherry J, Oehrlein K, Hegge K, Morgan B. Effect of burstmode transcutaneous electrical nerve stimulation on peripheral vascular resistance. Physical Therapy. 2001; 81(6):118391. PMID: 11380274

[32] Lundeberg T, Stener-Victorin E. Is there a physiological basis for the use of acupuncture in pain? International Congress Series. 2002; 1238:3-10. doi: 10.1016/s0531-5131(02)00416-8 